\title{
MECHANICAL STRENGTH OF COAL: METHODS OF DETERMINATION AND FACTORS OF INFLUENCE (REVIEW)
}

(c) V.V. Koval, D.V. Miroshnichenko, Doctor of Technical Sciences (State Enterprise "Ukrainian State Research Institute for Carbochemistry (UKHIN)", 61023, Kharkov, Vesnina st., 7, Ukraine)", O.V. Bogoyavlenska, PhD in technical sciences (National Technical University "Kharkiv Polytechnic Institute", 61002, Kharkiv, Kirpicheva st., 2, Ukraine)

The article substantiates the importance and problems of determining of such an indicator of the quality of solid fossil fuels, as mechanical strength. The strength of coal depends on a large number of factors (viscosity, brittleness, properties of structural bonds, etc.), the change of which is impossible to take into account. Therefore, the strength of coal in the sample, piece, pack and formation must be represented by some integral index, which inevitably fluctuates around a certain average value and can be determined only approximately. The evaluation of the strength properties of coal should be carried out on the basis of mass tests using statistical methods that allow to calculate the average value and coefficient of variation. Since the strength dispersion is mainly due to the natural inhomogeneity of the coal, the excessive accuracy of the measuring instruments has almost no effect on the statistical characteristics. Laboratory methods of mechanical tests of mine samples, in comparison with full-scale, as a rule, are very accessible and, at qualitative performance of tests, are highly reliable.

The properties of coal as an object of enrichment and use are largely related to its physical properties. The physical properties of coal and mineral impurities significantly affect the formation of the main parameters that characterize the particle size distribution and fractional composition, it s changes during the mining, transportation and enrichment processes.

The basic physical and mechanical properties of solid fuels from the point of view of their industrial processing have been listed, the review has been made of the most widespread methods of study of coals mechanical durability and the equipment used for these purposes. The main advantages and disadvantages have been summarized of these methods, as well as their relationship. The factors have been Indicated tinfluencing the mechanical strength of coal. The expediency of using existing methods from the point of view of informativeness for thesphere of its application has been estimated. The methods common in the coal processing industry are considered in more detail.

Keywords: coal, solid fuel mining, mechanical strength, determination methods, influencing factors, grinding strength, crushing index.

Corresponding authorV.V. Koval, e-mail: kovalen79@gmail.com 